\title{
Pressure pain sensitivity is associated with dental fear in adults in middle age: Findings from the Northern Finland 1966 birth cohort study
}

Rami Kankaanpää1 ${ }^{1,2,3 *}$, Juha Auvinen ${ }^{4,5,6 *}$, Kari Rantavuori ${ }^{7}$, Jari Jokelainen ${ }^{4,5,6}$, Jaro Karppinen ${ }^{4,6,8}$ and Satu Lahti ${ }^{1,9}$

${ }^{1}$ Department of Community Dentistry, University of Turku, Turku, Finland

${ }^{2}$ Oral and Maxillofacial Deceases, Tampere University Hospital, Tampere, Finland

${ }^{3}$ Oral Health Services, City of Tampere, Tampere, Finland

${ }^{4}$ Center for Life Course Health Research, University of Oulu, Oulu, Finland

${ }^{5}$ Unit of Primary Care, Oulu University Hospital, Oulu, Finland

${ }^{6}$ Medical Research Center Oulu, University of Oulu and Oulu University Hospital, Oulu, Finland

${ }^{7}$ Department of Oral Development and Orthodontics, University of Turku, Turku, Finland

${ }^{8}$ Finnish Institute of Occupational Health, Oulu, Finland

${ }^{9}$ Turku Clinical Research Centre, Turku University Hospital, Turku, Finland

*These authors contributed equally to the work 


\begin{abstract}
Introduction: Dental fear is a prevalent problem leading to severe deterioration of oral health and health-related quality of life. Despite the knowledge that dental fear is closely linked to painful experience, the association between pain sensitivity and dental fear remains unclear. This study was designed to evaluate this association with validated measures of dental fear and pressure pain sensitivity in a cohort population. Methods: The study population consisted of a subpopulation of the Northern Finland Birth Cohort 1966. At the age of 46 years, 1736 participants completed the valid and reliable Modified Dental Anxiety Scale (MDAS) and participated in a clinical examination, where their non-orofacial pressure pain sensitivity was evaluated by validated pressure pain threshold (PPT) and tolerance (PPTo) measurements. Gender-specific Tobit regressions were performed to analyze this association adjusted for smoking and depressive and anxiety symptoms. Results: Women with moderate dental fear had 5\% (31.3 kPa; $\mathrm{p}<0.05)$, and women with high dental fear had $7 \%$ (42.9 $\mathrm{kPa}$; n.s.) lower pressure pain threshold than women with low dental fear. Women with moderate dental fear had 4\% (35.4kPa; $\mathrm{p}<0.05)$ and women with high dental fear had 9\% $(82.7 \mathrm{kPa} ; \mathrm{p}<0.01)$ lower pressure pain tolerance than women with low dental fear. Men with moderate and high dental fear had 3\% (lower pressure pain tolerance $(35.4 \mathrm{kPa} ; \mathrm{p}<0.05$ and $29.6 \mathrm{kPa}$; n.s., respectively) than men with low dental fear, whereas the associations with pain threshold were not statistically significant. Among women, both anticipatory and treatment-related dental fears were associated with pain threshold and pain tolerance. Among men, pain threshold was associated with treatment-related dental fear only and the associations with pain tolerance were not statistically significant. Conclusions: Non-orofacial pressure pain threshold and tolerance appeared to be lower in participants with dental fear, which emphasizes the role of pain sensitivity in dental fear.
\end{abstract}




\section{Introduction}

Dental fear is prevalent among adult populations. ${ }^{1-3}$ In Finland, up to $50 \%$ of adults reported being at least somewhat afraid of dentistry and up to $10 \%$ reported high dental fear in nationally representative surveys in 2000 and 2011.,5 The main consequence of high dental fear is avoidance of dental treatment which may lead to severe deterioration of oral health and oral health-related quality of life. ${ }^{6-}$ 9

Dental fear has both exogenous (e.g. painful or unpleasant experiences) and endogenous (e.g. psychological disorders such as depressive or anxious symptoms) origin. ${ }^{10-14}$ Pain has been ranked among the most feared stimuli in dentistry ${ }^{15,16}$ and a large twin study recently confirmed that invasive treatment or pain composed one of the three subtypes of dental fear, with others being losing control and physical sensations. ${ }^{17}$

Despite the importance of pain in the etiology of dental fear, the role of pain sensitivity has not received much attention in research. Those with high dental fear have reported higher levels of pain sensitivity ${ }^{18}$, as well as expected pain ${ }^{19,20}$ and experienced pain ${ }^{20,21}$ than those with no or low dental fear. Pain sensitivity correlated positively with injection and drilling pain. ${ }^{22}$ However, these studies measured pain sensitivity with questionnaires and not in conjunction with experimental pain stimulus. When pain sensitivity was measured with heat and cold pressor in a twin study, the phenotypic correlation between dental fear and pain sensitivity indices were close to zero and environmental factors were emphasized. ${ }^{23}$ On the other hand, those with dental fear reported lower pain tolerance to electrical tooth pulp shock compared to non-fearful participants. However, there was no difference in pain tolerance to an experimental pain stimulus of arm nor in pain threshold to an experimental pain stimulus of tooth or arm between those with high or low dental fear. ${ }^{24}$ Those with dental fear have also reported higher pain in cold-water tests than those with low dental fear. ${ }^{21}$ However, these experimental studies on pain sensitivity or pain threshold in dental fear were conducted in selected, often small patient groups, and no population-based studies were found.

Thus, our aim was to investigate whether the pressure pain threshold and tolerance differs according to different levels of dental fear among 46-year-old participants in a large cohort study. Our hypothesis was that pressure pain sensitivity and tolerance are lower among those with high levels dental fear than among those with lower levels of dental fear. 


\section{Methods}

The study population is part of the Northern Finland Birth Cohort 1966 (NFBC1966; N=12 231, http://www.oulu.fi/nfbc). ${ }^{25}$ The cohort has been followed from antenatal age with regular questionnaire and clinical data collections (1, 14, 31 and 46 years). In the latest follow-up at the age of 46 years (in years 2012-2014), a subpopulation, living within 100km from the city of Oulu, was examined more intensively. In this area, 3150 participants were alive and had known addresses, of which 1964 responded (response rate 62.3\%). The questionnaires included items about dental wellbeing, health-related behavior and mental wellbeing. Dental anxiety was measured two hours before the clinical health examination. The Oral health examination was performed at the beginning of the clinical health examination followed by pressure pain threshold and tolerance measurements two hours later. Questionnaires inquiring smoking and mental wellbeing were filled out at home before the clinical examination. The study followed the principles of the Declaration of Helsinki. The Ethics Committee of the Northern Ostrobothnia Hospital District approved the research. Participants' rights have been protected by an appropriate Institutional Review Board and written informed consent was granted from all participants.

Dental fear was measured with the valid and reliable Finnish version of Modified Dental Anxiety Scale (MDAS). ${ }^{26-28}$ It includes five questions on how anxious one feels 1 ) the day before a dental appointment, 2) when in the waiting room, 3) waiting for the receipt of drilling, 4) waiting for the receipt of scaling and 5) waiting for the receipt of a local anaesthetic injection. Five response alternatives were 1 (not anxious), 2 (slightly anxious), (fairly anxious), 4 (very anxious) and 5 (extremely anxious), resulting in a total sum score of 5-25. MDAS was trichotomised as high dental fear $($ score $=19-25)$, moderate dental fear $($ score $=10-18)$ and no to low dental fear $($ score $=5-9) .{ }^{2}$ The MDAS has also shown to contain two factors: anticipatory dental anxiety (items 1 and 2, range 2-10) and treatment dental anxiety (items 3, 4 and 5, range 3-15). ${ }^{29}$ The factor scored were trichotomised based on their distribution.

Pressure pain threshold (PPT) and pressure pain tolerance (PPTo) were tested using an algometer (Somedic AB, Hörby, Sweden) with a $10 \mathrm{~mm}$ contact head, which was applied perpendicularly to the skin to produce pain. The algometer was chosen because it's computer-aided and the data it produces do not require conversion. The pressure was increased from $0 \mathrm{kPa}$ at a constant rate of $50 \mathrm{kPa} / \mathrm{s}$. 
Instructions to participants were, "A pressure will be applied at a gradual rate. Allow the pressure to increase until it reaches a point where it feels uncomfortable and then press the button down. As we continue increasing the pressure, release the button when you cannot tolerate the pressure any more". The former pressure value was recorded as the PPT and the latter as PPTo. Pressure was terminated at the latest when the safety maximum of $1200 \mathrm{kPa}$ was reached.

Standardized PPT and PPTo measurements were done for four anatomical sites in the following order: 1) shoulder; the mid belly of the upper trapezius muscle (participant in the prone position), 2) the mid belly of the tibialis anterior muscle (supine position), 3) the dorsal aspect of the wrist joint line (supine position), and 4) the L5/S1 interspinous space (prone position). The test sites were identified and participants were positioned in a standardized manner. Each site was tested two times and average value was used in the analysis. Each site was tested only two times, because even though a small piece of soft paper was used between the contact head and the skin to soften the sharp borders of the contact head, pressure caused imprint to skin, so adding repetitions was not justified. The exact anatomical point of pressure was shifted slightly between the tests due to prevent sensitization of nociceptors at the contact site.

Anxiety, depression and smoking were identified as potential confounders for both pain and dental fear at population level. ${ }^{14,30-32}$ Anxiety and depression were assessed with the 25 -item Hopkins Symptom Checklist at 46-years. A cut-off point of 1.55 was used to define anxiety and depression symptoms. ${ }^{33}$ Smoking history and present status was inquired with two questions at the age of 46 years: 1) "Have you ever smoked cigarettes (yes/no)?" and 2) "Are you currently smoking (yes/no)?" According to these questions, three categories were formed depending on smoking habits: 1) nonsmoker, 2) former smoker, and 3) current smoker.

As women consistently report higher levels of pain and dental fear, analyses were stratified by gender both for descriptive statistic and multivariate modelling. ${ }^{2,5,34}$ Mann-Whitney-tests and chi square-tests were used to assess differences between men and women. Tobit regression ${ }^{35}$ was performed to analyze the association between dental fear and PPT and PPTo. The motivation behind this is the large amount of censoring seen at the maximum limit of $1200 \mathrm{kPa}$, although the real PPTo might have been higher than this (i.e., ceiling effect). The adjustments were done for depression, anxiety and smoking. The interpretation of regression coefficients is not straightforward as it depends on the probability of not being censored. The interpretation is a combination of; 1) the change in outcome given it's not censored, weighted by the probability of not being censored; and 2) the change in the 
probability of not being censored, weighted by the expected outcome if uncensored. The analyses were performed with the R software ${ }^{36}$ using AER package for Tobit regression.

STROBE guidelines have been conformed in the study. 


\section{Results}

Women had higher mean values of dental fear both in total score and in the anticipatory and treatmentrelated fear subscores than men had. They also reported having anxiety and depressive symptoms and being non-smokers more often than men did (Table 1).

Both pressure pain threshold and tolerance at each site were lower in women than men (Table 2).

There were gender differences in the associations between dental fear total and factor scores and pain threshold and tolerance (Tables 3 and 4).

Women with moderate dental fear had 6\% (35.3 kPa; $<<0.01)$, and women with high dental fear had $9 \%(53.7 \mathrm{kPa} ; \mathrm{p}<0.05)$ lower pressure pain threshold than women with low dental fear. Corresponding percentages were $5 \%(34.2 \mathrm{kPa} ; \mathrm{p}<0.05)$ and $8 \%(50.6 \mathrm{kPa} ; \mathrm{p}<0.05)$, when adjusted for smoking. When adjusted also for anxiety and depressive symptoms, the corresponding percentages were 5\% $(31.3 \mathrm{kPa} ; \mathrm{p}<0.05)$ and $7 \%$ (42.9 kPa; n.s.) (Table 3).

For pain tolerance the association with dental fear was stronger. Women with moderate dental fear had 4\% (40.3 kPa; p<0.01) and women with high dental fear had 10\% (96.0 kPa; $<<0.01)$ lower pressure pain tolerance than women with low dental fear. Corresponding percentages were $4 \%$ (38.6 $\mathrm{kPa} ; \mathrm{p}<0.01)$ and $10 \%(90.6 \mathrm{kPa} ; \mathrm{p}<0.01)$, when adjusted for smoking. When adjusted also for anxiety and depressive symptoms, the corresponding figures were $4 \%(35.4 \mathrm{kPa} ; \mathrm{p}<0.05)$ and $9 \%(82.7 \mathrm{kPa}$; $\mathrm{p}<0.01)$ (Table 3).

Among men, only pain tolerance was statistically significantly associated with dental fear total scores. Men with moderate dental fear had 3\% (36.7 kPa; p<0.05) and men with high dental fear had 3\% (35.8 kPa; n.s.) lower pressure pain tolerance than men with low dental fear. Corresponding figures were $3 \%(36.9 \mathrm{kPa} ; \mathrm{p}<0.05)$ and $4 \%(40.2 \mathrm{kPa}$; n.s.) when adjusted for smoking. When adjusted also for anxiety and depressive symptoms, the corresponding figures were $3 \%(35.4 \mathrm{kPa} ; \mathrm{p}<0.05)$ and $3 \%$ (29.6 kPa; n.s.) (Table 3).

Among women, both anticipatory and treatment-related dental fears were associated with pain threshold and pain tolerance. Women with moderate anticipatory dental fear had $6 \%$ lower pain 
threshold and 5-6\% lower pain tolerance that women with low anticipatory dental fear. Women with moderate treatment-related dental fear had 6-7\% lower pain threshold and 6\% lower pain tolerance that women with low anticipatory dental fear. Among men, only treatment-related dental fear was associated with pain threshold. Men with high dental fear had 22-24\% lower pain threshold than men with low dental fear (Table 4). The estimates for the associations between dental fear and pain threshold and tolerance differed only slightly between models adjusted for smoking or both depressive/anxiety symptoms and smoking (Tables 3 and 4). 


\section{Discussion}

The associations between dental fear and non-orofacial pain threshold and tolerance differed among men and women. Both pain threshold and tolerance were associated with dental fear total score as well as with anticipatory and treatment-related dental fear among women. Among men, only pain tolerance was associated with dental fear total score and pain threshold with treatment-related dental fear. The associations were attenuated only slightly after adjustments for smoking and psychological disorders.

A strength of the current study is the large birth cohort data. To the authors' knowledge, this is the largest study to experimentally measure pain sensitivity using standardized equipment and its association with dental fear. The large data allowed for gender stratified analyses, as women have consistently reported higher levels of dental fear and pain. , $5,34^{2}$

Measuring pain sensitivity independent of dental fear and oral health examination could be considered a strength of the study. Similarly, performing pain sensitivity measurement in a non-craniofacial region of the body could be considered a strength. If pain would have been measured from orofacial region, it could have provoked dental fear conditioned from previous painful dental procedures. ${ }^{10,11}$ Patients with high dental anxiety have reported higher levels of pain from dental procedures. ${ }^{19,20}$ If pain would have been measured in conjunction with oral examination, a similar effect of conditioning might have affected the pain perception. Thus, our findings suggest that increased pain sensitivity, measured from non-orofacial region, may also contribute to the development of dental fear.

A weakness of the study is that dental fear was measured in conjunction with oral examination. The lower percentage of men with high dental fear in this study (2\%) compared to national survey (4\%) ${ }^{5}$ suggests that some of those with high dental fear might have avoided participation in the study due to oral examination. However, there were no systematic differences in pressure pain threshold and tolerance between those who participated in oral examination and who did not. Another weakness is that there was no or small variation in the pain tolerance measures among men because we did not press more than $1200 \mathrm{kPa}$ for safety reasons. Also, unlike in other studies ${ }^{34}$ pain sensitivity measurement was conducted only twice at each site. This might have resulted in higher average values compared to those obtained with a great number of measurements. ${ }^{37}$ Using cut-off points for the MDAS is also a limitation because the cut-offs are always somewhat arbitrary and result in loss of 
information. However, use of well-established cut-off points ${ }^{26}$ made it easier to interpret the findings of the regression analysis. Also, the cut-off points for the two factors of the MDAS are yet to be established. It must also be acknowledged that the confounding effect of smoking was evaluated based on self-reported smoking history by the participants, using a relatively crude estimate of smoking behaviour.

The lack of association between pain threshold and tolerance and dental fear among men might be due the possible drop-out among men with high dental fear and the fact that most men tolerated well the maximal pain stimulus level. In systematic analyses, gender has shown to affect experimental pain responses. ${ }^{38}$ and especially pain tolerance but not pain threshold. ${ }^{39}$ A similar gender difference in dental fear has consistently been reported ${ }^{1,2,5}$ but whether it is due to gender role has not to our knowledge been studied. ${ }^{40}$ On the other hand, women have ranked all dental care related stimuli more anxiety provoking than men. ${ }^{15}$ Thus, gender role affecting the report of pain and dental fear could be another explanation to the lack of association among men. However, rather strong relation was found between the pain threshold and treatment-related dental fear among men as well. This suggests that men with lower pain threshold might be more vulnerable to develop dental treatment-related fear, for example due to painful past experiences even in non-dental situations.

Findings of this large cohort study differ from previous studies on experimental pain in dental fear. ${ }^{23,24}$ In a former study, pain threshold and tolerance measured with arm pain stimulus were not associated with dental fear, but pain tolerance measured with pulp shock was. ${ }^{24}$ In a twin study with 188 participants, the phenotypic correlation between cold-pressure and heat pain and dental fear were close to zero. ${ }^{23}$ On the other hand, association between dental anxiety and cold-water pain was found among 102 dental patients. ${ }^{21}$ Other studies on pain sensitivity and dental fear have used nonexperimental measures of pain. ${ }^{18-20}$ The reasons for the differences between the findings might be due to the differences in study populations and sample sizes as well as the pain and fear measures used. Also, the time when participants reported their experienced pain has differed between studies as some studies have used questionnaires after the pain stimuli ${ }^{21,23}$ while in this and another study ${ }^{24}$ pain threshold and tolerance were registered during the experimental pain stimulus. The lack of associations between dental fear and experimental pain sensitivity in previous studies has been posited to be the result of some experimental pain stimuli not being relevant to the pain elicited from dental treatment ${ }^{23}$. Additionally, the contribution of psychological factors to pain sensitivity and experience has also been discussed to explain the contradictory findings ${ }^{23}$. However, our findings 
from a large cohort suggest that there is an association between dental fear and pain sensitivity, even when controlling for depressive and anxiety symptoms.

No assumptions can be made about the direction nor the causality of the associations observed in this cross-sectional study. For example, participants with lower pain tolerance and threshold might have been more easily conditioned to dental fear. On the other hand, dental fear due to painful dental procedures might have provoked fear of pain which might have further affected pain experience. Our study also looked only at the sensory dimension of pain and did not take into account emotional, cognitive or behavioral aspects of pain experience. Thus, more research using longitudinal design and including multiple aspects of pain and fear are needed to further understand this complex relationship.

In conclusion, pain threshold and tolerance appeared to be lower in middle-aged people with dental fear, especially among women. The association sustained even after adjustments for main psychological symptoms. This emphasizes the role of pain sensitivity in dental fear, which should be acknowledged in clinical practice, especially by avoiding pain with the use of appropriate local anesthesia. 


\section{Acknowledgements}

NFBC1966 received financial support from the Academy of Finland, University Hospital Oulu, University of Oulu, Finland, Northern Finland Health Care Foundation, Duodecim Foundation, Ministry of Education and Culture 86/626/2014, ERDF European Regional Development Fund Well-being and health: Research in the Northern Finland Birth Cohort 1966 (grant no. 539/2010 A31592, 01.01.2011-31.12.2013). The authors reported no conflict of interest. We express our sincerest gratitude to the field study team and study nurses who did all the examinations and data collections. We would also like to thank Professor Paula Rantakallio, who launched the NFBC1966. 


\section{References}

1. Armfield JM. The extent and nature of dental fear and phobia in Australia. Aust Dent J 2010;55:368-377.

2. Humphris G, Crawford JR, Hill K, Gilbert A, Freeman R. UK population norms for the modified dental anxiety scale with percentile calculator: adult dental health survey 2009 results. BMC Oral Health 2013;13:29.

3. Svensson L, Hakeberg M, Boman UW. Dental anxiety, concomitant factors and change in prevalence over 50 years. Community Dent Health 2016;33:121-126.

4. Lahti S, Vehkalahti MM, Nordblad A, Hausen H. Dental fear among population aged 30 years and older in Finland. Acta Odontol Scand 2007;65:97-102.

5. Liinavuori A, Tolvanen M, Pohjola V, Lahti S. Changes in dental fear among Finnish adults: a national survey. Community Dent Oral Epidemiol 2016;44:128-134.

6. Pohjola V, Lahti S, Vehkalahti MM, Tolvanen M, Hausen H. Association between dental fear and dental attendance among adults in Finland. Acta Odontol Scand 2007;65:224-230.

7. Pohjola V, Lahti S, Vehkalahti MM, Tolvanen M, Hausen H. Age-specific associations between dental fear and dental condition among adults in Finland. Acta Odontol Scand 2008;66:278-285.

8. Pohjola V, Lahti S, Suominen-Taipale L, Hausen H. Dental fear and subjective oral impacts among adults in Finland. Eur J Oral Sci 2009;117:268-272.

9. Armfield JM. What goes around comes around: revisiting the hypothesized vicious cycle of dental fear and avoidance. Community Dent Oral Epidemiol 2013;41:279-287.

10. Rachman S. The conditioning theory of fear-acquisition: a critical examination. Behav Res Ther 1977;15:375-387.

11. Weiner AA, Sheehan DV. Etiology of dental anxiety: psychological trauma or CNS chemical imbalance? Gen Dent 1990;38:39-43.

12. Locker D, Poulton R, Thomson WM. Psychological disorders and dental anxiety in a young adult population. Community Dent Oral Epidemiol 2001;29:456-463.

13. Armfield JM, Pohjola V, Joukamaa M, Mattila AK, Suominen AL, Lahti SM. Exploring the associations between somatization and dental fear and dental visiting. Eur J Oral Sci 2011;119:288-93.

14. Pohjola V, Mattila AK, Joukamaa M, Lahti S. Anxiety and depressive disorders and dental fear among adults in Finland. Eur J Oral Sci 2011;119:55-60. 
15. Oosterink FM, de Jongh A, Aartman IH. What are people afraid of during dental treatment? Anxiety-provoking capacity of 67 stimuli characteristic of the dental setting. Eur J Oral Sci 2008;116:44-51.

16. Humphris G, King K. The prevalence of dental anxiety across previous distressing experiences. J Anxiety Disord 2011;25:232-236.

17. van Houtem CMHH, van Wijk AJ, Boomsma DI, Ligthart L, Visscher CM, De Jongh A. The factor structure of dental fear. Eur J Oral Sci. 2017;125:195-201.

18. Klages U, Ulusoy O, Kianifard S, Wehrbein H. Dental trait anxiety and pain sensitivity as predictors of expected and experienced pain in stressful dental procedures. Eur J Oral Sci 2004;112:477-483.

19. Arntz A, van Eck M, Heijmans M. Predictions of dental pain: the fear of any expected evil, is worse than the evil itself. Behav Res Ther 1990;28:29-41.

20. Maggirias J, Locker D.. Psychological factors and perceptions of pain associated with dental treatment. Community Dent Oral Epidemiol 2002;30:151-159.

21. Kaakko T, Närhi M, Tuutti H. Association of dental anxiety and level of subjective pain experience. J Dent Res 1995;74(2 Suppl):1458.

22. Gross PR. Is pain sensitivity associated with dental avoidance? Behav Res Ther 1992;30:7-13.

23. Vassend O, Røysamb E, Nielsen CS. Dental anxiety in relation to neuroticism and pain sensitivity. A twin study. J Anxiety Disord 2011;25:302-8.

24. Klepac RK, Dowling J, Hauge G. Characteristics of clients seeking therapy for the reduction of dental avoidance: reactions to pain. J Behav Ther Exp Psychiatry 1982;13:293-300.

25. Rantakallio P. Groups at risk in low birth weight infants and perinatal mortality. Acta Paediatr Scand 1969;193(Suppl):1-71.

26. Humphris GM, Morrison T, Lindsay SJ. The Modified Dental Anxiety Scale: validation and United Kingdom norms. Community Dent Health 1995;12:143-50.

27. Humphris GM, Freeman R, Campell J, Tuutti H, D’Souza V. Further evidence for the reliability and validity of the Modified Dental Anxiety Scale. Int Dent J 2000;50:367370.

28. Viinikangas A, Lahti S, Yuan S, Pietilä I, Freeman R, Humphris G. Evaluating a single dental anxiety question in Finnish adults. Acta Odontol Scand 2007;65:236-240.

29. Yuan S, Freeman R, Lahti S, Lloyd-Williams F, Humphris G. Some psychometric properties of the Chinese version of the Modified Dental Anxiety Scale with cross 
validation. Health Qual Life Outcomes 2008;6:22.

30. Pohjola V, Mattila AK, Joukamaa M, Lahti S. Alcohol use disorder, smoking and dental fear among adults in Finland. Acta Odontol Scand 2013;71:300-306.

31. van Hecke O, Torrance N, Smith BH. Chronic pain epidemiology-where do lifestyle factors fit in? Br J Pain 2013;7:209-17.

32. Pohjola V, Rannanautio L, Kunttu K, Virtanen JI. Dental fear, tobacco use and alcohol use among university students in Finland: a national survey. BMC Oral Health 2014;14:86.

33. Veijola J, Jokelainen J, Läksy K, et al. The Hopkins Symptom Checklist-25 in screening DSM-III-R axis-I disorders. Nordic Journal of Psychiatry 2003;57:119-123.

34. Ostrom C, Bair E, Maixner W, et al. Demographic predictors of pain sensitivity: results from the OPPERA Study. J Pain 2017;18:295-307.

35. Tobin J. Estimation of relationships for limited dependent variables. Econometrica. 1958;26:24-36.

36. R Development Core Team. R: A language and environment for statistical computing. R Foundation for Statistical Computing, Vienna, Austria. 2015.

37. Lacourt TE, Houtveen JH, van Doornen LJP. Experimental pressure-pain assessments: Test-retest reliability, convergence and dimensionality. Scand J Pain 2012;3:31-37.

38. Alabas OA, Tashani OA, Tabasam G, Johnson MI. Gender role affects experimental pain responses: a systematic review with meta-analysis. Eur J Pain 2012;16:1211-1223.

39. Defrin R, Shramm L, Eli I. Gender role expectations of pain is associated with pain tolerance limit but not with pain threshold. Pain 2009;145:230-236.

40. Tolvanen M, Hagqvist O, Luoto A, et al. Changes over time in adult dental fear and correlation to depression and anxiety: a cohort study of pregnant mothers and fathers. Eur J Oral Sci 2013;121:264-269. 
Table 1. Characteristics of females and males at the age of 46-years according to their dental fear (MDAS=Modified Dental Anxiety Scale), anxiety and depressive symptoms and smoking. (p-values for chi-squaretests and Mann-Whitney-tests*)

\begin{tabular}{lccc}
\hline & $\begin{array}{c}\text { Females } \\
\mathbf{n = 9 2 2}\end{array}$ & $\begin{array}{c}\text { Males } \\
\mathbf{n = 8 1 4}\end{array}$ & p-value \\
\cline { 2 - 4 } MDAS total score & & & \\
Mean (SD) & $\mathbf{1 0 . 1}(\mathbf{4 . 5})$ & $\mathbf{8 . 2}(\mathbf{3 . 2})$ & $<\mathbf{0 . 0 0 1 *}$ \\
5-9 points & $55.6 \%$ & $73.0 \%$ & $<\mathbf{0 . 0 0 1}$ \\
10-18 points & $37.2 \%$ & $25.3 \%$ & $<\mathbf{0 . 0 0 1}$ \\
19-25 points & $7.2 \%$ & $1.7 \%$ & $<\mathbf{0 . 0 0 1}$
\end{tabular}

MDAS Factor 1

Anticipatory dental fear

$\begin{array}{lccc}\text { Mean (SD) } & \mathbf{3 . 5}(\mathbf{1 . 9}) & \mathbf{2 . 8}(\mathbf{1 . 3}) & <\mathbf{0 . 0 0 1} * \\ \text { 2-4 points } & 82.2 \% & 93.1 \% & <\mathbf{0 . 0 0 1} \\ \text { 5-8 points } & 14.4 \% & 6.4 \% & <\mathbf{0 . 0 0 1} \\ \text { 9-10 points } & 3.4 \% & 0.5 \% & <\mathbf{0 . 0 0 1}\end{array}$

MDAS Factor 2

Treatment-related fear

Mean (SD)

3-6 points

7-12 points

13-15 points

Anxiety symptoms

Yes $(\geq 1.55)$

\section{Depressive symptoms}

Yes $(\geq 1.55)$

\section{Smoking}

Current

Former

Non-smoker
$17.0 \%$

$12.7 \%$

$<0.001$

$26.6 \%$

$19.5 \%$

$<0.001$

$6.6(2.8)$

$5.4(2.1)$

$<0.001 *$

$62.3 \%$

$78.4 \%$

$<0.001$

$32.6 \%$

$20.6 \%$

$<0.001$

$1.0 \%$

$<0.001$

\section{$17.4 \%$}

$19.4 \%$

$<0.001$

$23.9 \%$

$34.0 \%$

$<0.001$

$58.8 \%$

$46.6 \%$

$<0.001$ 
Table 2. Pressure pain characteristics in 46-year-olds (median and 95\% confidence intervals) in females and males.

\begin{tabular}{lcccc}
\hline & \multicolumn{3}{l}{ Females } & \multicolumn{1}{l}{ Males } \\
\cline { 2 - 5 } Pressure pain threshold & $\mathrm{N}$ & Median (95\% CI) & $\mathrm{N}$ & Median (95\% CI) \\
\cline { 2 - 5 } Average & 844 & $591.9(579.7-607.0)$ & 776 & $790.8(768.7-807.3)$ \\
Leg & 897 & $590.3(568.5-609.6)$ & 795 & $911.8(886.7-947.3)$ \\
Low back & 888 & $652.3(628.1-674.3)$ & 778 & $819.5(786.0-850.5)$ \\
Shoulder & 900 & $487.1(470.7-504.9)$ & 796 & $605.5(583.2-638.9)$ \\
Wrist & 895 & $595.3(582.8-612.3)$ & 794 & $782.4(751.6-802.3)$ \\
Pressure pain tolerance & & & & \\
Average & 844 & $917.1(897.8-937.1)$ & 776 & $1157.8(1145.4-1168.9)$ \\
Leg & 897 & $920.4(889.5-952.9)$ & 795 & $1200.0(1200.0-1200.0)$ \\
Low back & 888 & $1019.4(982.8-1044.6)$ & 778 & $1200.0(1200.0-1200.0)$ \\
Shoulder & 900 & $860.4(833.1-879.9)$ & 796 & $1159.2(1128.5-1185.1)$ \\
Wrist & 895 & $885.7(867.9-907.9)$ & 794 & $1200.1(1198.3-1200.0)$ \\
\hline
\end{tabular}


Table 3. Tobit regression analysis of dental anxiety (MDAS) and pressure pain threshold and tolerance in females and males at the age of 46 -year. $\beta$-coefficient and $95 \%$ robust confidence intervals.

\begin{tabular}{|c|c|c|c|c|c|c|}
\hline & \multicolumn{3}{|c|}{ Pain threshold (kPa) ${ }^{1}$} & \multicolumn{3}{|c|}{ Pain tolerance $(\mathrm{kPa})^{1}$} \\
\hline & \multicolumn{3}{|c|}{ Coefficient (95\% CI) } & \multicolumn{3}{|c|}{ Coefficient (95\% CI) } \\
\hline & Crude & Model 12 & Model $2^{3}$ & Crude & Model 12 & Model $2^{3}$ \\
\hline \multicolumn{7}{|l|}{ Females $(n=884)$} \\
\hline Constant $^{4}$ & $\begin{array}{c}630.6 \\
(612.3,648.9)\end{array}$ & $\begin{array}{c}634.2 \\
(613.2,655.2)\end{array}$ & $\begin{array}{c}639.5 \\
(617.6,661.5)\end{array}$ & $\begin{array}{c}931.7 \\
(913.5,949.9)\end{array}$ & $\begin{array}{c}940.0 \\
(919.0,960.9)\end{array}$ & $\begin{array}{c}945.3 \\
(923.6,967.1)\end{array}$ \\
\hline
\end{tabular}

\section{$\operatorname{MDAS}^{5}$}

10-18 points

$$
-35.3 * *
$$

$-34.2 *$

$-31.1 *$

$-40.3^{* *}$

$-38.6 * *$

$-35.4 *$

$$
(-61.4,-9.2)
$$

$(-60.4,-8.0)$

$(-57.2,-4.9)$

$(-68.7,-12.0)$

$(-67.0,-10.3)$

$(-63.8,-7.1)$

19-25 points

$-53.7 *$

$-50.6^{*}$

$-42.9$

$-96.0 * *$

$-90.6 * *$

$-82.7 * *$

$(-103.2,-4.2)$

$(-100.8,-0.5)$

$(-93.8,8.0)$

$(-147.1,-44.9)$

$(-142.8,-38.5)$

$(-136.2,-29.3)$

Males $(\mathbf{n}=776)$

Constant $^{4}$

803.9

795.9

796.4

1140.9

1132.3

1135.6

(785.6, 822.1)

(771.1, 820.8)

(770.9, 821.9)

$(1127.5,1154.4)$

$(1114.4,1150.1)$

$(1117.4,1153.8)$

\section{MDAS $^{5}$}

$\begin{array}{ccccccc}\text { 10-18 points } & -24.3 & -23.4 & -25.0 & -36.7^{*} & -36.9^{*} & -35.4^{*} \\ & (-60.6,11.9) & (-59.7,13.0) & (-61.8,11.8) & (-66.6,-6.8) & (-67.1,-6.8) & (-65.5,-5.3) \\ & & & & & -40.2 & -29.6 \\ 19-25 \text { points } & -17.0 & -20.6 & -22.0 & -35.8 & (-134.3,54.0) & (-127.3,68.0)\end{array}$

${ }^{1}$ Average pressure pain threshold/tolerance of wrist, shoulder, low back and leg

${ }^{2}$ Adjusted for smoking

${ }^{3}$ Adjusted for smoking, depressive and anxiety symptoms

${ }^{4}$ Average pain threshold for participants belonging to reference group

${ }^{5}$ Reference group MDAS 5-9 points

$* \mathrm{p}<0.05 ; * * \mathrm{p}<0.01$ 
Table 4. Tobit regression analysis of anticipatory and treatment-related dental anxiety and pressure pain threshold and tolerance in females and males at the age of 46 -year. $\beta$-coefficient and $95 \%$ robust confidence intervals.

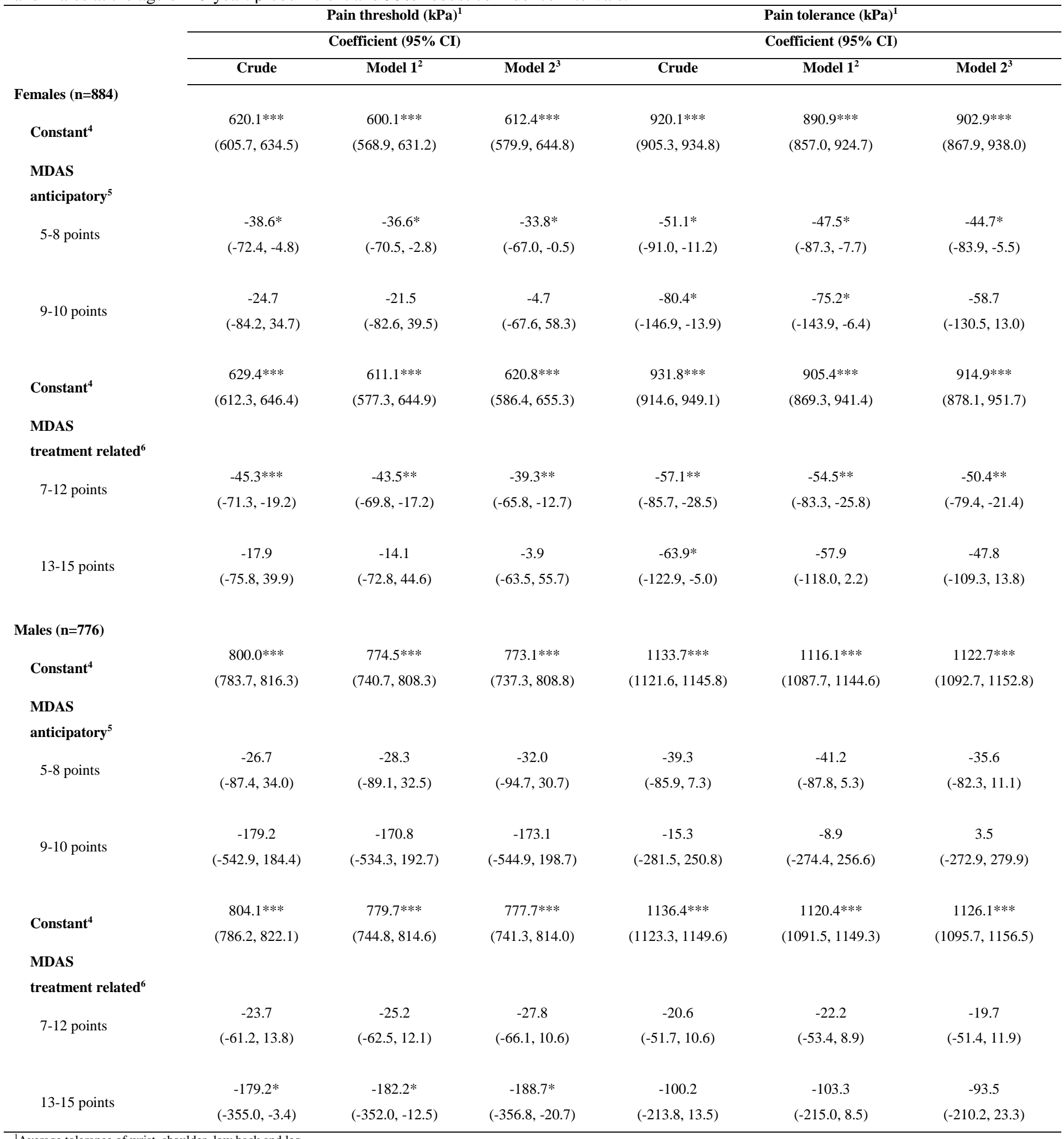

${ }^{2}$ Adjusted for smoking

${ }^{3}$ Adjusted for smoking, depressive and anxiety symptoms

${ }^{4}$ Average pain threshold for paticipants belonging to reference group

${ }^{5}$ Reference group MDAS anticipatory 2-4 points

${ }^{6}$ Reference group MDAS treatment-related 3-6 points

${ }^{*} \mathrm{p}<0.05 ;{ }^{* *} \mathrm{p}<0.01 ; * * * \mathrm{p}<0.001$ 